\title{
USE OF BIM TECHNOLOGY AS A SAFETY TOOL IN THE RESTORATION PHASE OF BUILDINGS: CASE STUDY OF THE FAÇADE OF THE "ROYAL TOBACCO FACTORY" IN SEVILLE, SPAIN
}

\author{
COSTANZA CIONI $^{1}$, MICHELE DI SIVO $^{1 *} \&$ DANIELA LADIANA ${ }^{2 \dagger}$ \\ ${ }^{1}$ Department of Energy, Systems, Territory and Construction Engineering, University of Pisa, Italy \\ ${ }^{2}$ Department of Architecture, University of Chieti and Pescara, Italy
}

\begin{abstract}
BIM technologies, which are rapidly spreading in the construction sector, are able to support all the phases of implementation of the construction process - from conception to demolition - regulating the entire life cycle of the building; however, the use of these, in most cases, is limited to the design phase only. The case described - studied in a degree thesis developed within the framework of the international cooperation agreement for research between the Faculties of Engineering and Architecture of the Universities of Pisa and Seville - explores the use of BIM as a useful technology for programming and managing the safety during the restoration of the façade of an important historic building located in Seville: the "Royal Tobacco Factory". The building, built between 1728 and 1771, served as a factory for the production of tobacco and cigars from its construction until 1950, when it was used as the seat of the Rectorate and some faculties of the University of Seville. Thanks to the use of Autodesk, Revit and STR vision CPM software, a simulation of all the phases of the work was carried out in order to understand how to reduce the levels of risk. The work process was broken down through the use of the "Work Breakdown Structure", a conceptual hierarchical structure branched on three levels. This operation has made it possible to obtain a general index of the works that contains the codes used by the software as a basis for the organization of work. On the STR Vision CMP BIM platform, it was possible to perform metric computation directly from the Revit model through the "Quantity Take Off" operation. The measures were thus linked through WBS codes with the estimation calculation and the Gantt diagram. Thanks to this type of approach, a 3D model was obtained that contains information not only on the geometry of the building but also on the spatial and temporal organization of the site and on costs. Further research includes the use of Autodesk Navisworks to run $4 \mathrm{D}$ simulations to refine the risk assessment and reveal many real issues in advance.
\end{abstract}

Keywords: BIM, case study, historical building, restoration phase, risk reduction.

\section{INTRODUCTION}

BIM technologies, to an increasing extent at the centre of studies, widely applied and popular for the optimization of the implementation of the building process, have been developed, since the seventies, thanks to the work of Charles M. Eastman, in the first form of "Building Product Models" [1], as "a digital representation of the building process which facilitates the exchange and interoperability of information in digital format" [2].

This first definition already highlighted interoperability and the possibility of managing the entire life cycle of a building through the creation of a virtual model as the fundamental contents of BIM; contents effectively reaffirmed as fundamental in the most recent definition of BIM developed by NBIMS (National BIM Standard-United States Project Committee). According to this, in fact, BIM is "a digital representation of physical and

\footnotetext{
* ORCID: http://orcid.org/0000-0002-2140-9513

$\dagger$ ORCID: http:// orcid.org/0000-0001-6008-1365
} 
functional characteristics of a facility. As such it serves as a shared knowledge resource for information about a facility and forms a reliable basis for decisions during its lifecycle from inception onward" [3].

The fundamental characteristics of this technology can be identified, therefore, not only in the three-dimensional digital representation of the building system but in the possibility of assuming BIM as an open and shared process of collaboration between the various operators and data management during the entire life cycle of a building, from design through to decommissioning. It is a functional technology to implement an integrated design system through the definition of a virtual model in which each element of the building organism is associated with specific characteristics (geometric, physical, material, cost, environmental, etc.) and continues with the phases of analysis, management, organization of the site or maintenance until any decommissioning [4].

Use of BIM not only permits achieving a model consisting of digital parametric elements but also putting all the actors in the process in relation to one another so as to be able to dialogue and collaborate at the same time, governing the flows of information and documentation through the different phases of the construction process. This technology entails, in fact, a substantial change in the design approach, implying skills and competences not only in the two/three-dimensional representation of the architectural elements but of all the information related to them. The model can in fact represent a real virtual simulation in which problems can be explored and solved digitally before proceeding in reality with the realization phases. BIM, through the three-dimensional parametric modelling of each design element, in fact aims to improve the quality and exchange of data, not only morphological, between the parties, reducing the number of errors, increasing the efficiency of the process and ensuring that the final result conforms to the design objectives. Moreover, from the point of view of method, it implements an important evolution in the actors of the building process, leading them to assume and carry out their roles in relation to the entire life cycle of the building [5].

The virtual model of the building organism, in addition to the geometry, can also contain precise time data and information on materials and related costs. The 4D model is defined as the one integrated by a time schedule able to visualize the time sequence of the construction; while 5D indicates the model to which the costs of the project materials and elements are added.

BIM technology is, in fact, currently mainly used in the design phase of new buildings, but a gradual extension of the use and study is being affirmed also for the optimization of further aspects of the building process and in reference also to the requalification of the existing building heritage and to the conservation of the historical-architectural building heritage, thus making possible the evolution of the culture and practice of design towards an essentially diachronic setting that aims at controlling all the phases of existence of the building system, not only as regards its generation but also its regulation.

This leads to an important paradigm shift, particularly in the design of complex organisms, with major repercussions on building quality thanks to real integration between the different design disciplines that govern the life cycle of the building and the growth of operator skills [5].

Among the various in-depth studies on the use of BIM to strengthen the governance capacity of the project in the various phases of the construction process, particular importance is given to the on-site construction phase, making it possible to achieve a significant improvement in terms of organization and safety through the strengthening of the ability to identify all possible risks. The visualization of all the representative moments 
of the site in a 3D model in continuous evolution, permits making interesting considerations about safety and in relation to possible interferences between one job and another.

\section{BIM FOR SAFETY OF THE RESTORATION SITE}

The use of BIM for defining virtual three-dimensional models closer to reality is configured as a useful technology to support the efficiency and effectiveness of on-site construction processes, improving the levels of organization and safety.

The possibility of simulating three-dimensionally not only the building in all its technological characteristics but also in all its construction phases, through the generation of a real virtual construction site, makes it possible to analyse, identify and minimize critical points and possible risks in advance, with obvious advantages in terms of programming and control of times and methods of work implementation [6].

The sharing of the model among the designers does in fact make it possible to solve possible interferences in the realization of the construction elements in the design stage so the project is able to satisfy technical and operational needs in terms of ergotechnics, planning and coordination of work in relation to workers' safety and health protection measures [6].

BIM facilitates the management of the construction of the building by improving the organizational aspects related to the continuous modification of the production site over time, permitting the updating of worksite assets as a result of the progress of the work and the changes that occur during the job performance period. What is strengthened, thanks to the construction of the virtual model of the building and the construction site, is the ability to simulate the construction process in all its phases, concretely approaching operational reality and thus avoiding that abstractness which currently undermines the usefulness of many safety plans, based on descriptions of works and generic risks and not concretely related to the situations of the specific context [7].

The importance of using BIM technology for security planning and management is particularly evident in worksites for the restoration of buildings of historical and monumental importance, where the need exists to analyse and deal with further levels of complexity linked to the value and connotations of the building and its context. In this context, design activities are faced not only with the delicate operation of identifying the appropriate operational techniques of intervention on the building, but with the dynamic analysis of spatial and temporal flows of construction resources, technological, human and material, and of the necessary preparations in terms of support logistics, in sites that are both degraded and of significant importance for the community [8].

It is not possible, in fact, to assimilate the complexities inherent in the worksite for the construction of a new building with those of work carried out on an existing building and, moreover, of high historical value. The latter often differs in terms of the type of personnel, work, machinery and equipment and the difficulties involved in organizing the use of the spaces.

The architectural heritage characterized by historical, artistic and cultural value, is often the bearer of specific conditions regarding the methods of implementation of possible conservation, consolidation or restoration jobs. Most often, this is the case in old-town centres, which are very dense and closed, often difficult to access by standard construction means. Moreover, these buildings often host major public functions, which cannot be completely interrupted and, therefore, it is necessary to provide for forms of site organisation compatible with continued use, ensuring the highest levels of safety for operators and users. The organization of the site, in such situations, must also take into account further goals: to ensure the protection of the building; minimize the physical and 
perceptual impact of the work installations, allowing the widest and most comfortable aesthetic and functional enjoyment of the building during the period in which work is in progress [8]. In the context of the development of BIM technologies for the optimisation of worksite safety, it is therefore necessary to define methods and carry out experiments to maximise their effectiveness in governing work done in the historical and monumental building sector, directing their use towards the construction of multi-dimensional site models capable of fully describing and representing the work phases so as to identify all possible risks for workers [9].

Although the issue of the organization and safety of construction sites is a relevant one for the optimization of the building process, only a limited number of studies continue to address the matter of how to design and manage safe construction based on the use of BIM and fewer still focus on restoration sites.

This document, through an in-depth investigation of a case study, outlines a possible path aimed at safety planning through the implementation of an information system and technical requirements for safety based on BIM. The results of the project, which must be validated by a real project, are intended as a development platform for: i) a methodological guide for construction and safety professionals on the types of safety management which BIM can conduct; ii) how to use information in BIM to generate a safety model (e.g. object identification, geometric attributes, safety rules).

The study - further delved into by a degree thesis developed within the framework of the international cooperation agreement for research between the Faculties of Engineering and Architecture of the Universities of Pisa and Seville - explores the use of BIM as a useful technology to program and manage security during the restoration of the façade of an important historical building located in Seville: the "Royal Tobacco Factory" [10].

The working hypothesis was to apply BIM tools in the project execution phase, focusing on safety management, adopting as a methodological approach the use not only of the faithful representation of the objects that make up the building organism but the detailed identification and description of the work processes achieved through the application of a branched structure at three levels: the WBS, Work Breakdown Structure, to a portion of a façade. The software used for the project is Autodesk Revit, STR vision CPM, and Autodesk Navisworks Simulate [11].

\section{THE "ROYAL TOBACCO FACTORY" IN SEVILLE: THE CASE STUDY}

The history of the tobacco industry in Spain is closely linked to Seville for its function in colonial times as the main port of traffic with the Americas which resulted in the city taking on the role of major production and marketing site. All the tobacco coming from Virginia and from all the Spanish colonies where it was grown converged here, and it was here that the entire production process took place, from raw material through to end product manufacture. The variety originally produced was tobacco powder for which mills were needed to crush the dry leaf to bring it to the consistency of a fine powder. It was only in the late 17 th century that cigar production began [12].

The first tobacco factory in the western world was, therefore, founded in Seville around 1620 in a building near the church of San Pedro at the initiative of Jorge Bautista Carrafa. At the beginning of the 18th century, given the substantial production, space in the old factory proved insufficient and the construction began of a new and extremely large building near the College of San Telmo. The building of this new facility began in 1728 and took almost 40 years to finish (1763), although production had already begun by 1757 . Hence a majestic industrial building, the largest in Spain, took shape [13]. 


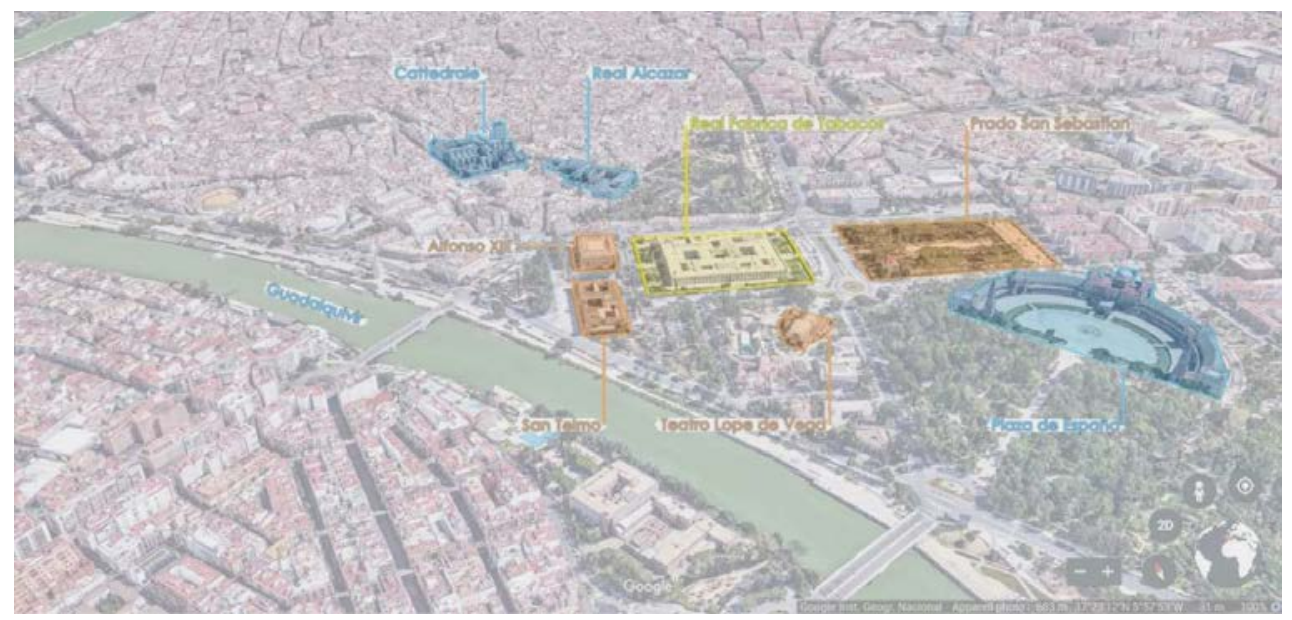

Figure 1: Location of the "Royal Tobacco Factory" in Seville. (Source: Authors.)

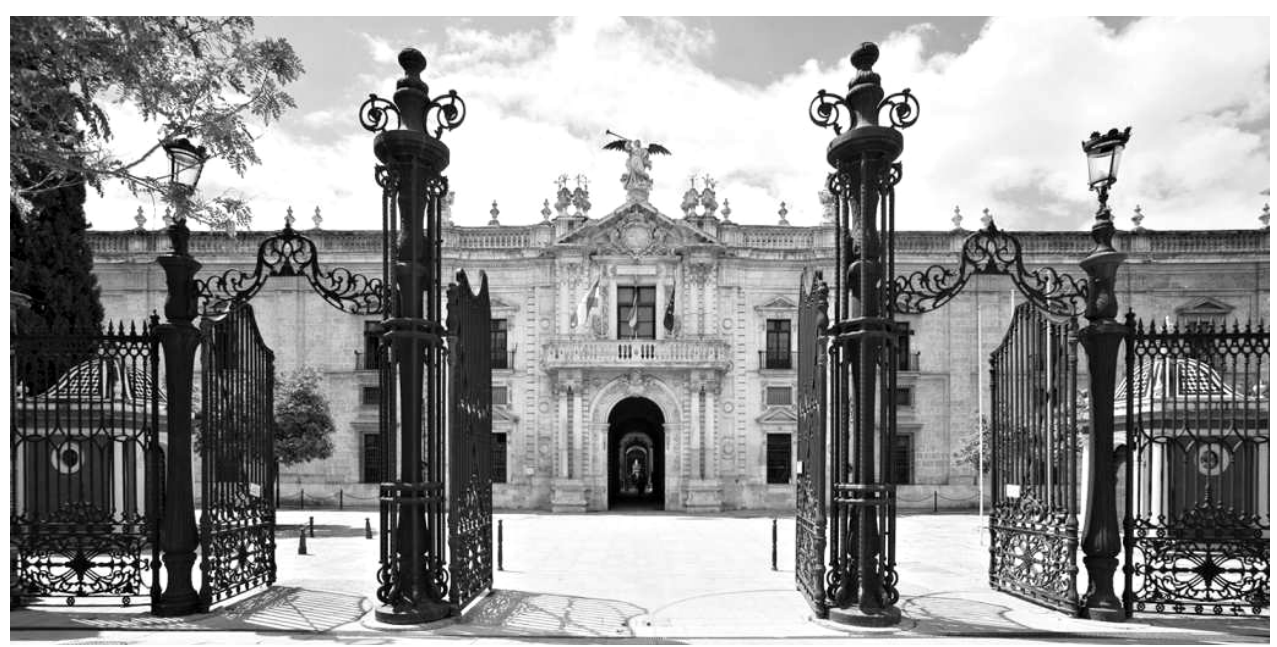

Figure 2: Main façade of the "Royal Tobacco Factory" on Calle San Fernando. (Source: Authors.)

Work began on a project by the engineer Ignacio Sala (Figs 1 and 2). The most important transformations occurred between 1750 and 1771, under the supervision of the Dutch engineer Sebastian Van Der Borcht [12].

When city expansion encountered the area in which the building was located, in the early 20th century, this became a key element for organising the area. In 1950, the decision was taken to convert the tobacco factory into the seat of the University of Seville, so the internal layout of the building had to undergo major transformation in order to adapt to its new function. The project, which dates back to 1953, was conceived by Antonio Balbontin de Orta, A. Delgado Roig and Antonio Toro Buiza. 


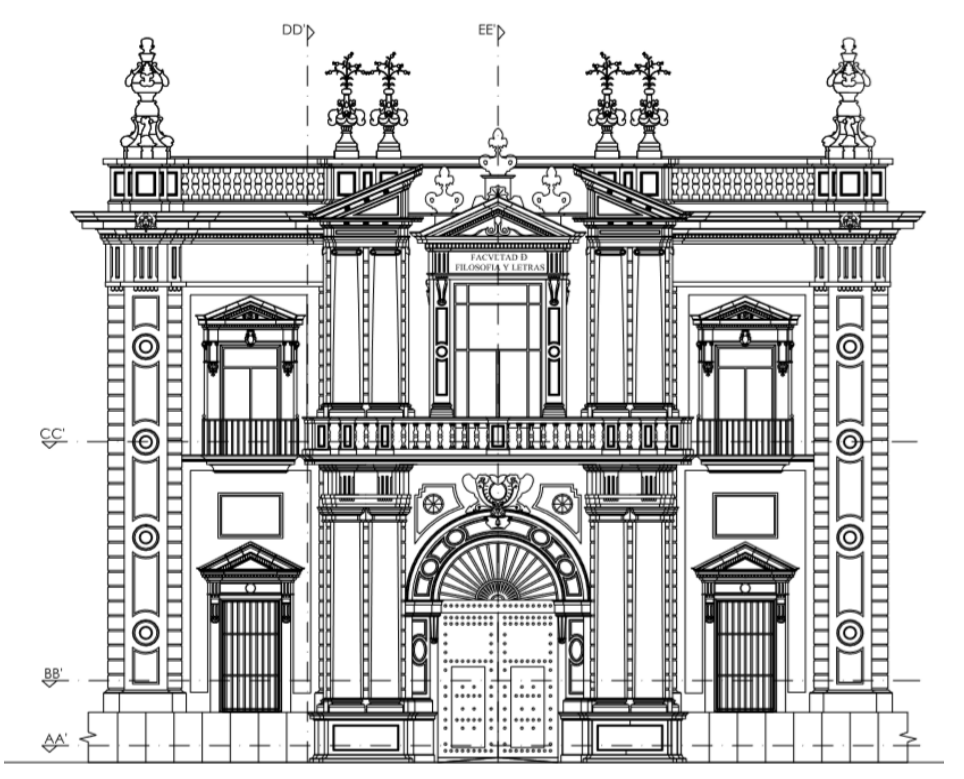

Figure 3: Elevation of the portal of Calle Padilla. (Source: Authors.)

Since 1954, the building has therefore been the seat of the Rectorate of the University and of the faculties of law, literature and science. Today, the tobacco factory is one of the oldest preserved industrial buildings in Europe [14].

The 2006 restoration project was conceived by architect D. Juan Manuel Macías, professor at the University of Seville (Fig. 3).

Restoration was essentially required because of the state of deterioration of the walls. The sandstone of the external façades and patios had in fact gradually deteriorated.

The material, after having resisted for more than three centuries, due to the action of atmospheric agents, had progressively lost its internal cohesion, also causing the alteration of the iron compounds within, which, after becoming oxidized, had increased in volume. This had resulted in the appearance of lesions which had produced the detachment of a number of projecting elements. The less sunny walls (external façades and the north and west courtyards) were the most affected.

The main restoration jobs involved: cleaning, consolidation, repositioning, filling of joints and cracks in the masonry works and waterproofing and replacement of the balcony floors. With regard to the section of the façade affected by experimental simulation, i.e. the restoration of the portal on calle Maria de Padilla, the architectural elements involved in the restoration, on the two levels of the façade, starting from the bottom, were: base, vertical coating, base of the columns, stem, capitals, balustrade, main balcony, central pediment, frieze, frames, decorative brackets, the four openings, including pediments, jambs and lintels, decorative elements (vases, shields, pillars), iron elements. The surface area involved, not counting the upper decorations, was about $446.34 \mathrm{~m}^{2}$.

With regard to the organisational aspects of the worksite, the design guidelines were taken from the "Estudio básico de Seguridad y Salud" (document corresponding to the Safety and Coordination Plan in Italian legislation) prepared by Geyser S. L. 
The installation procedures took into account the need to allow the building to be used while work was in progress: in order to protect against the danger of objects falling from above, the passage from the access door to the building was, in fact, made possible through the construction of a covered path, before the $1.75 \mathrm{~m}$ long row of scaffolding.

Access to the worksite for personnel and vehicles was provided from the left wing of the scaffolding where there is both access to the scaffolding, through a staircase, and the pre-sorted waste collection area which acts as an area for the storage of materials, loading/unloading and workstation on the ground.

\section{THE METHODOLOGICAL APPROACH}

In order to carry out a modelling experiment aimed at optimizing the levels of safety and organization of the restoration site, the worksite layout and the modelling of the scaffolding were developed for carrying out work at the entrance portal of the west façade of the main building, towards calle Dona Maria de Padilla, which belongs to the Faculty of Philosophy and Letters of the University of Seville.

From a methodological point of view, during experimentation, the most relevant aspect was the application of the WBS, the Work Breakdown Structure; an approach developed by the Project Management Institute of Philadelphia, which involved the breaking down of the work phases according to a branched structure on three levels (see Fig. 4). It is an analytical breakdown which makes it possible to visually obtain an idea of the work required to complete the planned project, in order to improve the ability to better evaluate actions. The WBS can be used not only to effectively break down the project execution phases but also to improve price estimation and more accurately determine the completion of operations.

The WBS is usually represented in graphical (tree structure) or descriptive (index structure) form. With regard to worksite activities, the use of WBS makes it possible to improve communication between the different actors and to better understand everything that happens during the work execution process. Each activity is unambiguous, since it is

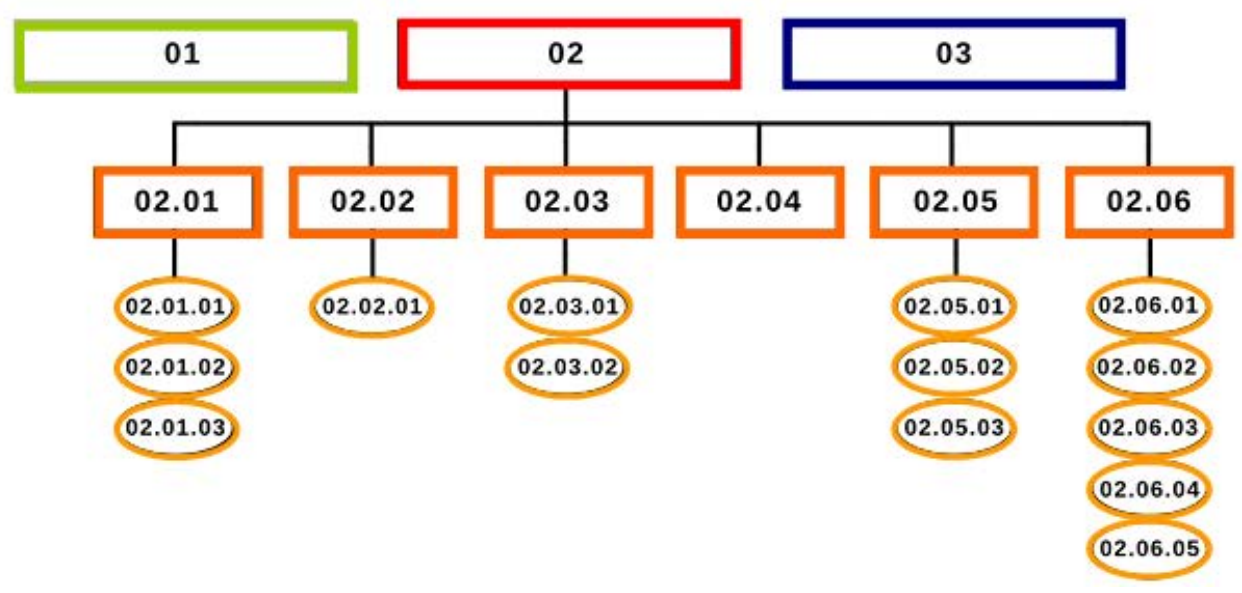

Figure 4: The Work Breakdown Structure (WBS) is an approach which involved the breaking down of the work phases according to a branched structure on three levels. Each level of the WBS is a level of detail created by decomposition, a process of breaking down the work into smaller components called tasks. (Source: Authors.) 
described clearly and completely. Each task is the responsibility of a single person and there is no risk of duplicating performed activities. In addition, the use of WBS, permits breaking down all the activities of the site into the smallest details, making them clearly understandable to all those involved in carrying out the work [15].

The aim is to identify and place work packages (deliverables) at the last clearly manageable hierarchical level so that they can be planned, scheduled, budgeted, monitored and evaluated. Each package keeps the structural laws of the system alive: objective (what to do), action (how to do it), resources (who does it, with what), organisation (roles of responsibility). Each element or macro activity of the WBS is called the Work Breakdown Element (WBE). At the lowest level of the WBS (at the last break-down level) we identify the Work Packages.

The whole organizational process is broken down into a Work Breakdown Structure; this allows us to have a general index of the works, containing the codes used by the software to define each work phase. To do this we focused on the survey chapter dedicated to the construction site organization. For the simulation phase two comparing software were used: STR Vision CPM and Navisworks Simulate [16] (Fig. 5).

STR Vision CPM is an Italian software of quantity surveying that contains a BIM platform for the IFC model vision. It allows linking the model, the measurements and the GANTT diagram to directly execute the simulation. There are two possibilities to do the 3D linked quantity survey: one is to manually execute the quantity take off from each model family and for each WBS work package. This option is relatively simple although quite cumbersome. The alternative is to create a parametric calculation of the quantity survey that contains the detection rules set for each item, repeatable for all the different levels of WBS. Once this procedure has been performed, by updating the model the measurements and the calculations are automatically updated at the same time. Each work package can be associated with one or more elements in the model. In this way, it is possible to create visualization styles to represent temporal phases and the works progress. The elements can

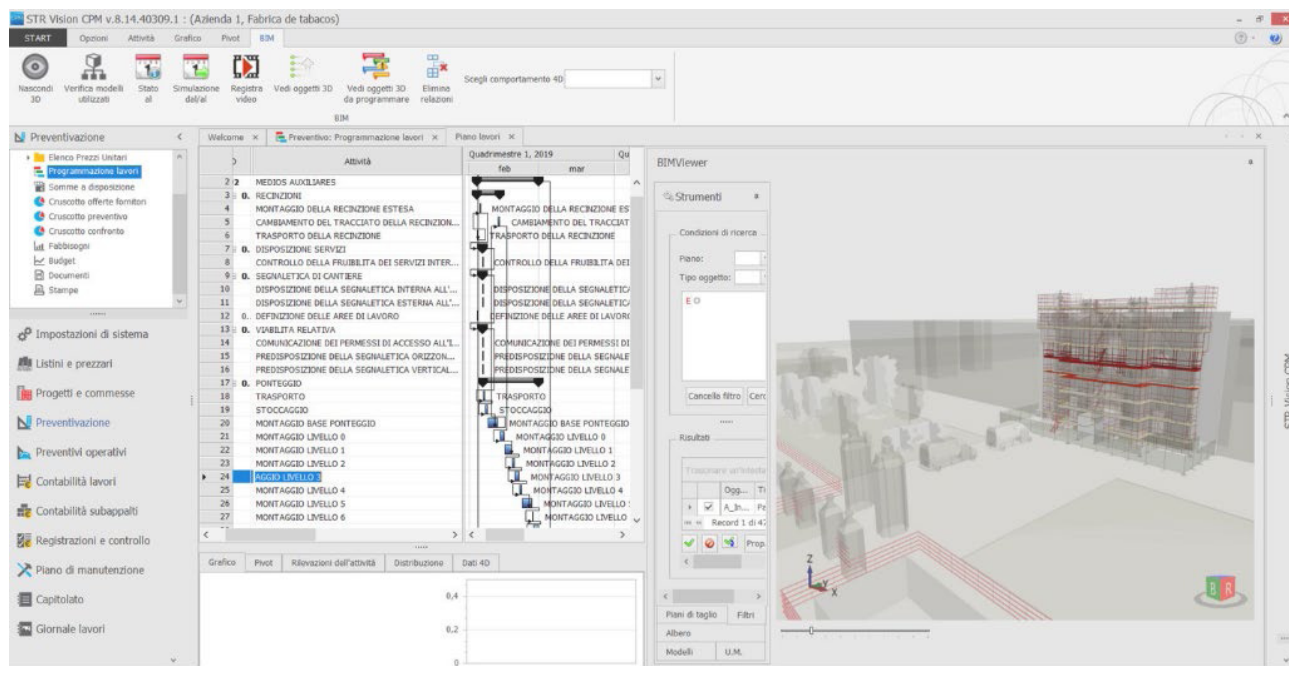

Figure 5: Workspace in STR Vision CPM and in Autodesk Navisworks Simulate. (Source: Authors.) 
be differentiated between computed and non-computed, or work to be performed, executed or in execution. This allows the development of a realistic simulation of the works throughout the duration of the construction site. At the end, the simulation can be recorded as a video.

Navisworks Simulate belongs to the Autodesk group and can be used to perform simulations starting from a previous time schedule. It is set up to work in agreement with other Autodesk software and with Project MS. The interface is very intuitive and the importing procedure of the model, directly in .rvt format, is optimal. Unlike STR, the model is imported as a link, so when the base file changes, the simulation is automatically updated as well. Simulations can also be carried out by manually reporting the temporal phases on the timeline.

\section{THE SCAFFOLDING PROJECT}

In the project experimentation activities forming the subject of this study, scaffolding represents the element with the greatest difficulties from a geometric and organizational point of view [17] (Fig. 6).

In the modelling phase, the articulation of the monumental façade has been effectively simplified through the use of the generic model category family, to describe the size and shape of the elements and be able to relate effectively to the geometry of the scaffolding.

Available from scaffolding manufacturers are more or less detailed models, linked to real catalogues, but supplied as plug-ins for AutoCAD and therefore for a purely geometric and not parametric rendering of the project.

The initial step was then to decide how to model a scaffolding that could be processed specifically to perform a Quantity take off on STR Vision or, at least, to obtain a complete abacus of the elements.

The choice was to find an existing catalogue and remodel from scratch all the objects needed for the model, creating families that directly contain all the information provided by the manufacturer. For this purpose, the catalogue of PERI, a German company, was chosen,

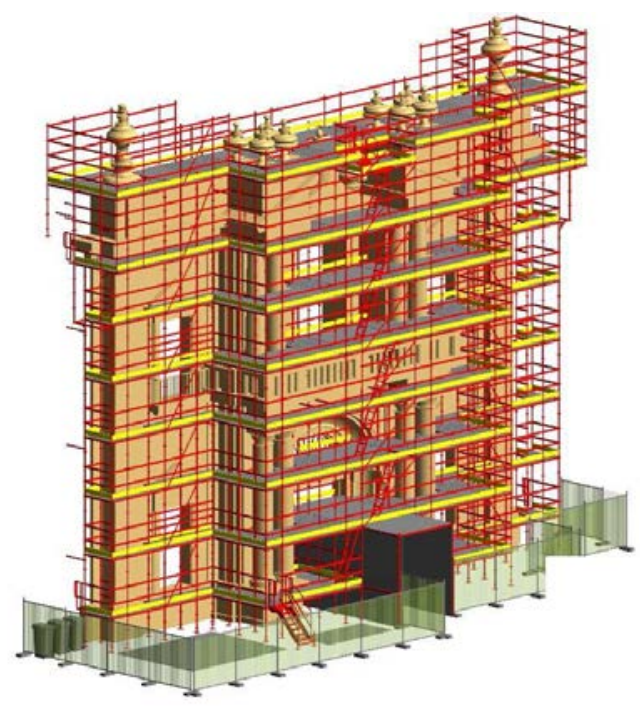

Figure 6: 3D model of the scaffolding and the portal on Autodesk Revit. (Source: Authors.) 
since among its products is a scaffolding called PERI UP façade Flex, specifically designed to be particularly flexible and solve even small gaps on complex façades.

Each element of the catalogue used in the model has been redesigned with a LOD $350-400$, starting with the geometric information provided in the catalogue. The detail of the joints was not represented in the model, but the geometries necessary for the joint to be effective were respected. This way, a catalogue of families was created, belonging to the Generic models category containing among the type properties: the manufacturer's parameters, a reference code to the original catalogue, the construction phase and the WBS code to connect to the calculation [18]. The same properties were also included among the Instance properties so that they could also be easily referred to on the IFC model on other platforms, other than the Revit interface.

The details of all the working phases are provided below. The definition of the construction site plan and the layout of the fences has been defined in accordance with the project's needs, paying attention to the critical issues of the site organization.

1. First, the geometry of the scaffolding base was drawn, marking the supports in plan at ground floor level. It is necessary to adapt the design to the complex geometry of the building and respect the limitations according to safety regulations. To build the 3D Revit model, a virtual catalogue of Revit families of generic models was created. This catalogue contains all the pieces necessaries to compose the scaffolding design and the models are based on a real catalogue of a scaffolding constructor.

2. After the creation of the scaffold geometry framework at the ground floor, eight structural layers are superimposed. The basic elements are repeated, in vertical alignment, for the number of levels required creating seven levels, each one of $2 \mathrm{~m}$.

3. Now, the clash detection starts. It highlights the points where the scaffold structure interferes with the façade elements. Once the clashes have been identified, they must be solved by the designer using the "subtraction" method. He eliminates the critical elements and he studies, case by case, an alternative design to solve the structure (see Fig. 7).

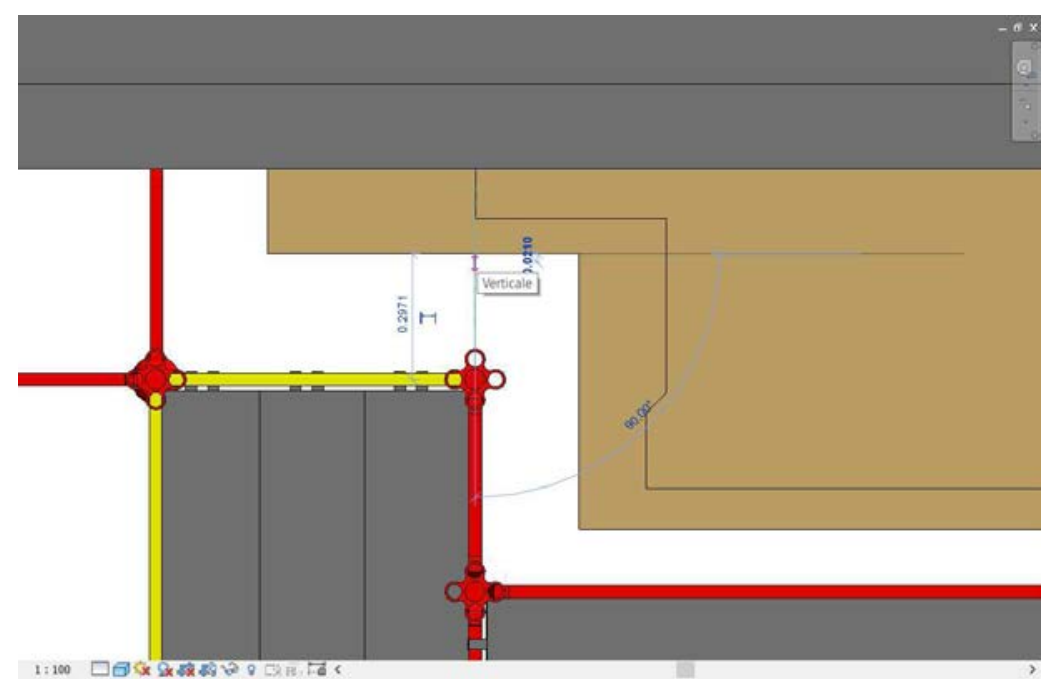

Figure 7: Scaffolding safety analysis. Individuation of a empty space. (Source: Authors.) 
4. It is now necessary to fill all the gaps between the internal edge of the scaffolding and the façade. The goal is to ensure that at no point there are empty spaces with a depth greater than $20 \mathrm{~cm}$. By analyzing the plants of each level and manually measuring the distances of the edges from the façade, the designer can find the critical points (Fig. 8).

5. Using a certified modular structure, it is only necessary to verify that the load limits of the catalogue are respected. As for stability and resistance to the wind, the anchors have been placed every $20 \mathrm{~m}^{2}$ and each façade has been stabilized with diagonals on the front (Fig. 9).

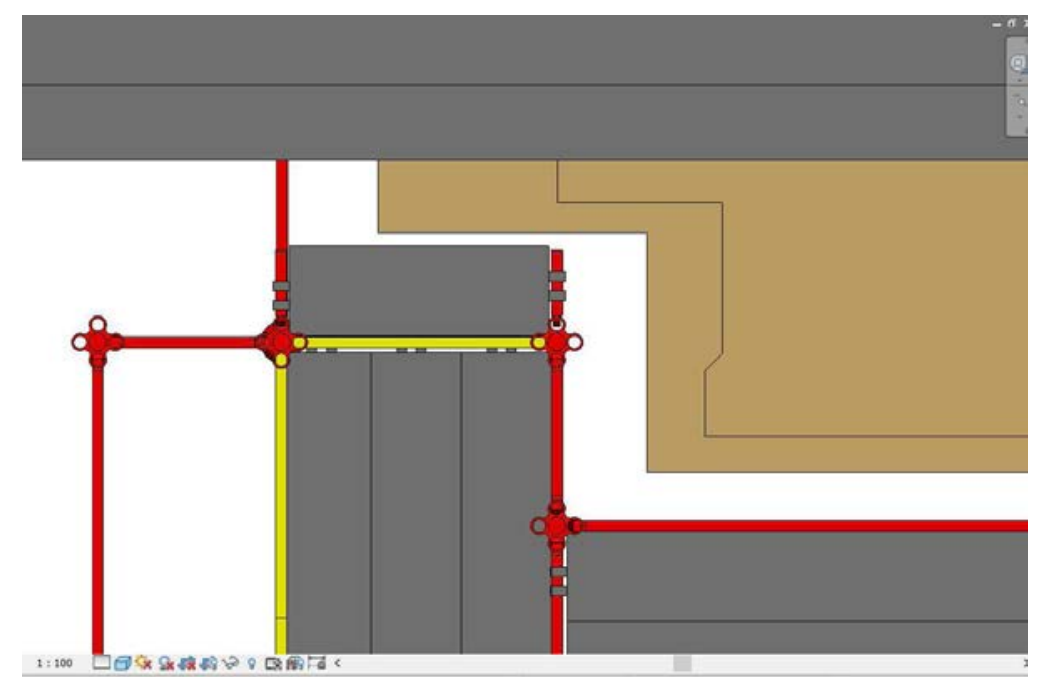

Figure 8: Scaffolding safety analysis. Solution for empty spaces. (Source: Authors.)

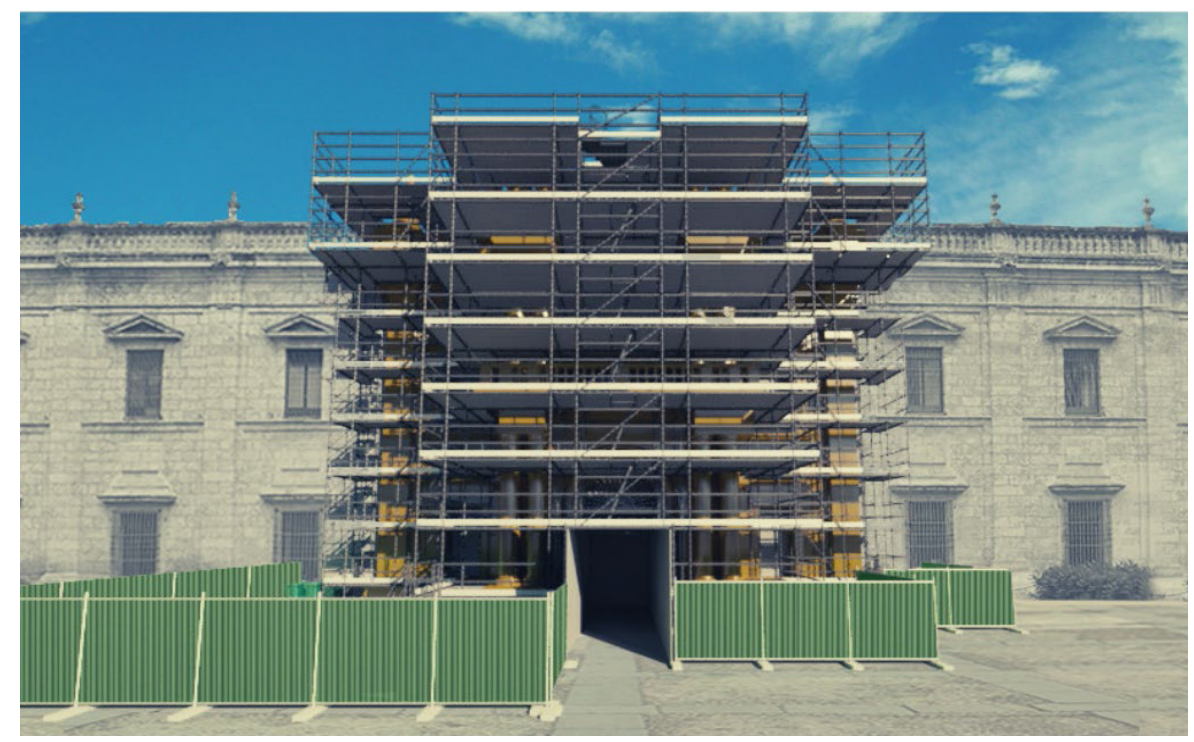

Figure 9: 3D model of the scaffolding. (Source: Authors.) 
6. One of the most important aspects of modelling is the creation of an abacus that helps understanding and elaborating the model. Two key abacuses were created for this project. One that lists the parameters of the "type" with temporal phases and one with the properties of the "instances", in parallel with the type parameters.

\section{CONCLUSIONS}

It is very important to be able to predict and anticipate the interferences and the unforeseen events that may occur on the construction site because they represent the greatest risks in the safety field.

That is the reason why safety is not a phase of the project, but it is a constant that accompanies all the project timeline and every work package. Specifically, BIM can help safety management by visualization, communication, and education improvement.

Nowadays the potential of the technology is impressive, for sure the studies to be pursued in this field should refer essentially to the method. It is important to understand that new technologies need new researches and frameworks to be applied. The legislative, economic and professional apparatus is not now properly prepared to work with this philosophy. It is absolutely necessary to catch up with the times.

The study on the method performed in this research could also be applied in other areas of design; it represents a line of thought to share with different disciplines, to facilitate the integration of technology with a concrete organizational process.

\section{ACKNOWLEDGEMENTS}

The case study was developed as the Master Degree thesis entitled "IT procedure for construction site simulation on complex buildings - Study of the scaffolding for the restoration of the Antigua Real Fábrica de Tabacos of Seville" by the post-graduate student in Building Engineering - Architecture Costanza Cioni, and reviewed by professors Michele Di Sivo, Daniela Ladiana, Massimiliano Martino, María Rosario Chaza Chimeno and Juan Manuel Macías Bernal, in collaboration with the University of Pisa and the University of Seville.

\section{REFERENCES}

[1] Quirk, V., Brief history of BIM, Archdaily, 7 Dec. 2012. www.archdaily.com/ 302490/a-brief-history-of-bim/.

[2] Eastam, C., Building Product Models: Computer Environments Supporting Design and Construction, CRC Press, 2018.

[3] National Institute of Building Sciences, Innovative solutions for the built environment. www.nationalbimstandard.org/about.

[4] Osello, A., Il Futuro del disegno con il BIM per Ingegneri e Architetti, Flaccovio Dario Editore: Torino, 2012.

[5] Gökgür, A., Current and Future Use of BIM in Renovation Projects, Chalmers UT, 2015.

[6] Chan, I.Y.S., Leung, H.Y., Fung, I.W.H. \& Leung, M., How can BIM support construction safety management? Development of SIM. MATEC Web Conference, 2016.

[7] Gibb, A., Haslam, R., Hide, S. \& Gyi, D., The role of design in accident causality. Designing for Safety and Health in Construction, eds S. Hecker, J. Gambatese \& M. Weinstein, University of Oregon Press: Oregon, 2004.

[8] Biagini, C., Capone, P., Donato, V. \& Facchini, N., Procedures for Simulation of Historical Building Restoration Site, IT Firenze, 2015. 
[9] Sadeghia, H., Mohandesb, S.R. \& Abdul, A.R., Reviewing the usefulness of BIM adoption in improving safety environment of construction projects. Jurnal Teknologi, 2016.

[10] Pomares Torres, J.C., Baeza, F.J., Varona Moya, F.B. \& Bru, D., BIM implementation for structural design courses in civil engineering. Building Information Modelling (BIM) in Design, Construction And Operations II, WIT Press: Southampton and Boston, 2017.

[11] Pomares Torres, J.C., Baeza, F.J., Varona Moya, F.B. \& Bru, D., Revisión del uso de building information modeling en la educación superior relacionada con la arquitectura, ingeniería y construcción. Investigación en Docencia Universitaria. Diseñando el Futuro a Partir de la Innovación Educativa, ed. R. Roig-Vila, Editorial Octaedro, 2017.

[12] Morales Sánchez, J., La Real Fábrica de Tabacos: Arquitectura, Territorio y Ciudad en la Sevilla del Siglo XVIII, Seville, 1991.

[13] Rodriguez Gordillo, J.M., Sevilla y el Tabaco, Seville, 1984.

[14] Gonzáles Vilchez, M., Plan Director de Remodelación de la Fábrica de Tabacos de la Universidad de Sevilla, Seville, 2009.

[15] Project Management Institute, A guide to the project management body of knowledge, Philadelphia, 2017.

[16] Raineri, A.A.C. \& Scoglio, M., BIM management e fase di esecuzione - Modelli operativi per la caratterizzazione del cantiere e delle azioni di controllo, Milano, 2014.

[17] Trani, M., Cassano, M., Todaro, D. \& Bossi, B., BIM Level of Detail for Construction Site Design, 2016.

[18] Feng, C.W. \& Lu, S.W., Using BIM to Automate Scaffolding Planning for Risk Analysis at Construction Sites, Taiwan, 2017. 